Kansas State University Libraries

New Prairie Press

\title{
SOME RESULTS ON THE DESIGN OF EXPERIMENTS FOR COMPARING UNREPLICATED TREATMENTS
}

\author{
R. J. Martin \\ J. A. Eccleston \\ N. Chauhan \\ B. S. P. Chan
}

See next page for additional authors

Follow this and additional works at: https://newprairiepress.org/agstatconference

Part of the Agriculture Commons, and the Applied Statistics Commons

\section{(c) (1) $\Theta(9$}

This work is licensed under a Creative Commons Attribution-Noncommercial-No Derivative Works 4.0 License.

\section{Recommended Citation}

Martin, R. J.; Eccleston, J. A.; Chauhan, N.; and Chan, B. S. P. (2004). "SOME RESULTS ON THE DESIGN OF EXPERIMENTS FOR COMPARING UNREPLICATED TREATMENTS," Conference on Applied Statistics in Agriculture. https://doi.org/10.4148/2475-7772.1157

This is brought to you for free and open access by the Conferences at New Prairie Press. It has been accepted for inclusion in Conference on Applied Statistics in Agriculture by an authorized administrator of New Prairie Press. For more information, please contact cads@k-state.edu. 
Author Information

R. J. Martin, J. A. Eccleston, N. Chauhan, and B. S. P. Chan 


\title{
SOME RESULTS ON THE DESIGN OF EXPERIMENTS FOR COMPARING UNREPLICATED TREATMENTS
}

\author{
R. J. Martin ${ }^{1}$, J. A. Eccleston², N. Chauhan ${ }^{3}$ and B. S. P. Chan ${ }^{4}$ \\ ${ }^{1}$ Wirksworth, Derbyshire DE4 4EB, UK; \\ 2School of Physical Sciences, University of Queensland, Brisbane, Qld 4072, Australia; \\ 3Prosthetics Molecular Design Ltd, Runcorn, Cheshire, UK; \\ ${ }^{4} \mathrm{ABN}-$ Amro Bank, Hong Kong, China.
}

Dedicated to the memory of R. A. Kempton, 1946-2003

\begin{abstract}
In early generation variety trials, large numbers of new varieties may be compared, and little seed is usually available for each variety. A so-called unreplicated trial has each new variety on just one plot at a site, but includes several (often around 5) replicated check or control (or standard) varieties. The total proportion of check plots is usually between $10 \%$ and $20 \%$. The aim of the trial is to choose some (around 1/3) good performing varieties to go on for further testing, rather than precise estimation of their mean yield.
\end{abstract}

Now that spatial analyses of data from field experiments are becoming more common, there is interest in an efficient layout of an experiment given a proposed spatial analysis. Some possible design criteria are discussed, and efficient layouts under spatial dependence are considered.

\section{Introduction}

The improvement of crop varieties can have a major impact, for example in reducing the amount of land, fertilizer, and pesticides which are needed for a given amount of food. New crop varieties are continually being developed by plant breeders, which then undergo lengthy testing, with statutory requirements, before they can be used commercially.

There are usually many new varieties, with little available seed. At each experimental station, the new varieties are usually (as assumed here) unreplicated, but the experiment includes several (typically 1 to 5) replicated control, or check, varieties. Since the aim is to select about a third of the new varieties for further testing, it is not clear what is a good but simple criterion for choosing between designs.

Additional complications are that although it is often possible to postulate in advance with some confidence, from extensive past experience, the form of the spatial dependence, the parameters of the process cannot be predicted so accurately, and the postulated process itself may not be appropriate.

Thus it is desirable that the design should be robust to mild differences from the postulated structure, and that the design should allow efficient estimation of the parameters of the process, 
an efficient check of whether the process is appropriate, and, if necessary, an efficient diagnosis and estimation of a different process.

The design problem for an unreplicated field trial is essentially that of allocating the check varieties to $\mathrm{n}$ plots out of the total $\mathrm{m}$ plots available, and secondly allocating the check varieties to those selected sites - see Figure 1 . Typically, $\mathrm{m}$ will be several hundreds, and $\mathrm{n} / \mathrm{m}$ between $10 \%$ and $20 \%$. The plots are usually rectangular, but not usually square, so the dependence could be expected to be roughly the same in both directions, or much stronger in one direction (along which the long sides adjoin) - see Figure 2.

The layout of the control plots has in the past usually been systematic - see e.g. Federer and Raghavarao (1975), Kempton (1984), Besag and Kempton (1986), Kempton and Talbot (1988). Examples include every third plot in a row having the control, with a single shift from one row to the next, leading to the control plots forming diagonal strings (i.e. in strings of diagonally adjacent plots); and two controls occupying every sixth column, alternating within each column. The latter arrangement was thought to be reasonable if plots are long and narrow, and similar designs have been widely used in Britain. Figure 3 shows two examples.

\section{Models, analyses and criteria}

Interest is usually in selecting about the best third of the new varieties for further testing. Various methods for ranking the new varieties have been used over the years. Early methods adjusted the yield of each new variety according to the yields of nearby controls (possibly after adjustment for variety and block effects, etc) - see, e.g. Besag and Kempton (1986). Note that other criteria, such as quality, may also be important.

We consider here an experiment at just one site, and suppose that the $\mathrm{m}=\mathrm{p}_{1} \mathrm{p}_{2}$ plots are in a $\mathrm{p}_{1} \times \mathrm{p}_{2}$ rectangular array, and that there are c control varieties, replicated $\left\{\mathrm{r}_{\mathrm{i}}\right\}$ times, with $\Sigma \mathrm{r}_{\mathrm{i}}=\mathrm{n}$. Thus there are $t=m-n$ test varieties, and we are only concerned here with the allocation of the $n$ control sites. The $\mathrm{m}$ sites are assumed to be ordered lexicographically (by columns within rows).

Suppose here that the analysis postulates a linear model for the observations $y: E(y)=T \tau, \operatorname{var}(y)$ $=\mathrm{V} \sigma_{\mathrm{y}}{ }^{2}$, and uses generalized least-squares estimation.

Methods which take into account the spatial dependencies in the yields have been recently suggested (Cullis et al., 1989, 1998). Recent practice in NSW Agriculture, Australia uses a spatial model for the dependence fitted by ASREML (Gilmour et al., 1995). Their initial spatial model includes terms for random row and column effects, a superimposed spatial dependence modelled as a separable AR1*AR1, and an independent white noise (or measurement error), so that

$$
\mathrm{V} \sigma_{\mathrm{y}}^{2}=\mathrm{I}_{\mathrm{P}_{1} \mathrm{p}_{2}} \sigma_{0}^{2}+\mathrm{J}_{\mathrm{P}_{1}} \otimes \mathrm{I}_{\mathrm{p}_{2}} \sigma_{1}^{2}+\mathrm{I}_{\mathrm{p}_{1}} \otimes \mathrm{J}_{\mathrm{P}_{2}} \sigma_{2}^{2}+\Lambda_{1} \otimes \Lambda_{2} \sigma_{3}^{2}
$$


where $\mathrm{J}_{\mathrm{p}}$ is a $\mathrm{p} \times \mathrm{p}$ matrix of ones, $\Lambda_{\mathrm{k}}=\left(\alpha_{\mathrm{k}}{ }^{|\mathrm{i}-\mathrm{j}|}\right)$; and $\alpha_{1}$ and $\alpha_{2}$ are the within-column and withinrow AR1 parameters. Here we concentrate on results for the AR1*AR1, i.e. in eq. (1) $\sigma_{0}^{2}=\sigma_{1}^{2}$ $=\sigma_{2}{ }^{2}=0, \sigma_{\mathrm{y}}{ }^{2}=\sigma_{3}{ }^{2}$, so that $\rho_{\mathrm{g}, \mathrm{h}}=\operatorname{corr}\left(\mathrm{y}_{\mathrm{i}, \mathrm{j}}, \mathrm{y}_{\mathrm{i}+\mathrm{g}, \mathrm{j}+\mathrm{h}}\right)$, the correlation at lags g, h, equals $\rho_{\mathrm{g}, 0 \rho_{0, \mathrm{~h}}}$ $=\alpha_{1}|\mathrm{~g}| \alpha_{2}|\mathrm{~h}|$, and assume non-negative correlations, $\alpha_{1}, \alpha_{2} \geq 0$. Results for the more general model are discussed in Chan et al. (1999), Chauhan et al. (2000), Martin et al. (2000). Some design comparisons under some other dependence assumptions are in Maas et al. (2002).

Here we assume the mean $\mathrm{E}(\mathrm{y})$ only depends on the $\mathrm{c}+\mathrm{t}$ variety effects, which are treated here as fixed effects. Note that it may be appropriate in some cases to treat the new variety effects as random, and the check variety effects might then be taken as either fixed or random. Some investigations of design under these assumptions are in Chauhan et al. (2000), Maas et al. (2003).

In practice, the analysis may also include high-order polynomial or spline surfaces treated as fixed or random effects.

Let $\mathrm{C}$ denote $\mathrm{T}^{\prime} \mathrm{V}^{-1} \mathrm{~T}$, the usual C-matrix. Then $\hat{\tau}=\mathrm{C}^{-1} \mathrm{~T}^{\prime} \mathrm{V}^{-1} \mathrm{y}$ with $\operatorname{var}(\hat{\tau})=\mathrm{C}^{-1} \sigma_{\mathrm{y}}{ }^{2}$. For design purposes, assume $\mathrm{V}$ is known.

When all (pairwise) contrasts are of equal interest, it is reasonable to minimise the average scaled variance (i.e. ignoring $\left.\sigma_{\mathrm{y}}{ }^{2}\right)$ of pairwise contrasts, $\{2 /(\mathrm{c}+\mathrm{t}-1)\}\left\{\operatorname{tr}\left(\mathrm{C}^{-1}\right)-1^{\prime} \mathrm{C}^{-1} 1 /(\mathrm{c}+\mathrm{t})\right\}$. This is the the A-criterion. However, since selection is (mainly) by ranking, which is not amenable for design purposes, it is not clear what is a sensible design criterion to use in this situation.

Several possible criteria have been considered previously - see, e.g. Federer and Raghavarao (1975). These include the A-criterion, and minimizing the average scaled variance between test and control varieties ( $A_{n s}$-criterion), or the average scaled variance between test varieties $\left(A_{n n}{ }^{-}\right.$ criterion). Although the $A_{n n}$-criterion seems more natural for this situation, we shall see its use is not always satisfactory. If the $A_{s s}$-value is that for the average scaled variance between the control varieties, then

$$
(\mathrm{c}+\mathrm{t})(\mathrm{c}+\mathrm{t}-1) \times(\mathrm{A}-\mathrm{value})=2 \mathrm{ct} \times\left(\mathrm{A}_{\mathrm{ns}}-\text { value }\right)+\mathrm{t}(\mathrm{t}-1) \times\left(\mathrm{A}_{\mathrm{nn}}-\text { value }\right)+\mathrm{c}(\mathrm{c}-1) \times\left(\mathrm{A}_{\mathrm{ss}}-\text { value }\right),
$$

If, as usual, c/t is small, we have the approximate relationship:

$$
\text { A-value } \approx \mathrm{A}_{\mathrm{nn}} \text {-value }-2 \mathrm{ct}^{-1} \times\left\{\left(\mathrm{A}_{\mathrm{nn}} \text {-value }\right)-\left(\mathrm{A}_{\mathrm{ns}} \text {-value }\right)\right\} \text {, }
$$

i.e. the A-value is usually nearly linearly related to the $A_{n n}$ - and $A_{n s}$-values (exactly so if $c=1$ ), and is usually close to the $\mathrm{A}_{\mathrm{nn}}$-value.

Example 1. The A-, $A_{n n^{-}}, A_{n s}{ }^{-}$, and $A_{s s}$-values for some designs with $\mathrm{p}_{1}=5, \mathrm{p}_{2}=10, \mathrm{~m}=50$, $\mathrm{n}=10, \mathrm{t}=40$, are given in Table 1 . Firstly, there are the values for $\mathrm{V}=\mathrm{I}_{\mathrm{m}}$ (any layout); for $\mathrm{c}=2, \mathrm{r}_{1}$ 
$=r_{2}=5$; and $c=1, r_{1}=10$. Then there are the values for two designs $(\mathrm{DC}(3,8), \mathrm{DR}(3)$ in $\S 4)$ under an AR1*AR1 dependence structure with $\alpha_{1}=0.2, \alpha_{2}=0.6$, in the alternating and repeated cases (subscripts a and $r$ ) for $c=2, r_{1}=r_{2}=5$; together with those for $c=1, r_{1}=10$ (subscript 1 ). The $\left\{\mathrm{a}_{\mathrm{i}}\right\}$ are defined later. Note how closely the $\mathrm{A}$ - and $\mathrm{A}_{\mathrm{n}}$-values are related, and, within either of the two designs, how the A- and $\mathrm{A}_{n n}$-values hardly differ over the three cases, but the $A_{n s}$-value for the repeated case is somewhat larger than the other two. Also, see the values for $\mathrm{V}=\mathrm{I}_{\mathrm{m}}$ and $\mathrm{DR}(3)$, the $\mathrm{A}$-value for $\mathrm{c}=1$ can be larger than when $\mathrm{c}=2$. []

Some simulations suggest that usually the A-, $A_{n n}-, A_{n s}$-values correlate well (negatively) with selection probabilities - see Figure 4 for an example, which shows some $A_{n n}$ - and $A_{n s}$-values for an $8 \times 20$ array, with $c=2, r_{1}=r_{2}=10, t=140$, and eq. (1) with $\sigma_{0}^{2}=1 / 4, \sigma_{1}^{2}=1 / 8, \sigma_{2}^{2}=3 / 4, \sigma_{3}^{2}$ $=3 / 4, \sigma_{3}^{2}, \alpha_{1}=0.2, \alpha_{2}=0.6$, and considers the probability that the best 7 varieties are in the 35 selected. For this, 15 designs expected to be good and 15 expected to be bad were chosen, as well as 120 random ones. The treatment effects were generated from a $\mathrm{N}(0,1)$ distribution, and for each design y was simulated 5000 times. Then the treatment effects were estimated using generalised least-squares assuming $\mathrm{V}$ was known. Note the spread in probabilities and criteria values among the random designs, and that all were well above the designs expected to be bad. Also, note the difference between the two criteria for the designs expected to be bad. They form two clumps, which are reasonably close for the $A_{n n}$-values, but further apart for the $A_{n s}$-values, although the selection probabilities are fairly similar. In this example, the Spearman rank correlations are -0.87 and -0.86 , respectively. Over the other examples considered, the $A_{n n}$ value usually correlates very slightly better than the $A_{n s}$-value with selection probabilities. The $A$ - and $A_{n n}$-values are extremely highly correlated, and so henceforth only the $A_{n n}$ - and $A_{n s^{-}}$ values are discussed.

To obtain efficient designs for a typically large $\mathrm{m}$ and a general $\mathrm{V}$, an algorithmic approach can be used. A hybrid algorithm based on simulated annealing, and using exchanges between varieties at sites, has been developed (Martin \& Eccleston, 1997), and used on some examples. For large $\mathrm{m}$, the basic algorithm can take a long time to produce very good designs as $\mathrm{C}$ is of size $\mathrm{t} \times \mathrm{t}$, and hence $\mathrm{C}^{-1}$ is time-consuming to calculate. However, since most varieties are unreplicated, $\mathrm{T}$ has a simple form, and some matrix manipulations can dramatically reduce the computation needed.

Reorder the plots with the control plots first, so that $y^{\prime}$ becomes $\left(y_{s}^{\prime} y_{n}^{\prime}\right)$, $T$ becomes $\operatorname{diag}\left(T_{s}, T_{n}\right)$, and $V$ becomes $\left[\begin{array}{cc}V_{s s} & V_{s n} \\ V_{n s} & V_{n n}\end{array}\right]$, where $y_{s}$ is the vector of observations on the control plots, $E\left(y_{s}\right)=$ $\mathrm{T}_{\mathrm{s}} \tau$, and $\operatorname{var}\left(\mathrm{y}_{\mathrm{s}}\right)=\mathrm{V}_{\mathrm{ss}} \sigma_{\mathrm{y}}{ }^{2}$, etc. Let $\mathrm{V}_{\mathrm{nn} . \mathrm{s}}$ denote $\mathrm{V}_{\mathrm{nn}}-\mathrm{V}_{\mathrm{ns}} \mathrm{V}_{\mathrm{ss}}{ }^{-1} \mathrm{~V}_{\mathrm{sn}}$, and let $\mathrm{M}_{1}=\mathrm{T}_{\mathrm{s}}{ } \mathrm{V}_{\mathrm{ss}}{ }^{-1} \mathrm{~T}_{\mathrm{s}}, \mathrm{M}_{2}=$ $\mathrm{T}_{\mathrm{s}}{ }^{\prime} \mathrm{V}_{\mathrm{ss}}{ }^{-1} \mathrm{~V}_{\mathrm{sn}}$. Note that $\mathrm{M}_{1}$ is the C-matrix for the control varieties, and $\mathrm{V}_{\mathrm{nn.s}} \sigma_{\mathrm{y}}{ }^{2}$ is $\operatorname{var}\left(\mathrm{y}_{\mathrm{n}} \mid \mathrm{y}_{\mathrm{s}}\right)$ in the conditional distribution for $\mathrm{y}_{\mathrm{n}} \mid \mathrm{y}_{\mathrm{s}}$, which has $\mathrm{E}\left(\mathrm{y}_{\mathrm{n}} \mid \mathrm{y}_{\mathrm{s}}\right)=\mathrm{T}_{\mathrm{n}} \tau+\mathrm{V}_{\mathrm{ns}} \mathrm{V}_{\mathrm{ss}}{ }^{-1}\left(\mathrm{y}_{\mathrm{s}}-\mathrm{T}_{\mathrm{s}} \tau\right)=\left(\mathrm{T}_{\mathrm{n}}-\mathrm{M}_{2}{ }^{\prime}\right) \tau$ $+\mathrm{V}_{\mathrm{ns}} \mathrm{V}_{\mathrm{ss}}{ }^{-1} \mathrm{y}_{\mathrm{s}}$. 
Then, $\quad C^{-1}=\left[\begin{array}{cc}0 & 0 \\ 0 & V_{n n . s}\end{array}\right]+\left[\begin{array}{c}I_{C} \\ M_{2}^{\prime}\end{array}\right] M_{1}^{-1}\left[I_{c} M_{2}\right]$, and the $A_{n n^{-}}$and $A_{n s}$-values are given by

$$
\begin{gathered}
\{(\mathrm{t}-1) / 2\} \times\left(\mathrm{A}_{\mathrm{nn}} \text {-value }\right)=\mathrm{a}_{1}-\mathrm{a}_{2}+\mathrm{a}_{3}-\mathrm{a}_{4} \geq \mathrm{a}_{1}-\mathrm{a}_{2} \text { and } \\
\operatorname{ct} \times\left(\mathrm{A}_{\mathrm{ns}}-\text { value }\right)=\mathrm{c}\left(\mathrm{a}_{1}+\mathrm{a}_{3}\right)+\mathrm{ta}_{5}-2 \mathrm{a}_{6} \geq \mathrm{ca}_{1},
\end{gathered}
$$

where $\mathrm{a}_{1}=\operatorname{tr}\left(\mathrm{V}_{\mathrm{nn} . \mathrm{s}}\right), \mathrm{a}_{2}=\mathrm{t}^{-1} 1_{\mathrm{t}}{ }^{\prime} \mathrm{V}_{\mathrm{nn.s}} 1_{\mathrm{t}}, \mathrm{a}_{3}=\operatorname{tr}\left(\mathrm{M}_{2}{ }^{\prime} \mathrm{M}_{1}{ }^{-1} \mathrm{M}_{2}\right), \mathrm{a}_{4}=\mathrm{t}^{-1} 1_{\mathrm{t}}{ }^{\prime} \mathrm{M}_{2}{ }^{\prime} \mathrm{M}_{1}{ }^{-1} \mathrm{M}_{2} 1_{\mathrm{t}}, \mathrm{a}_{5}=\operatorname{tr}\left(\mathrm{M}_{1}{ }^{-1}\right)$, $\mathrm{a}_{6}=1_{\mathrm{c}}{ }^{\prime} \mathrm{M}_{1}{ }^{-1} \mathrm{M}_{2} 1_{\mathrm{t}}$. Table 1 gives the $\left\{\mathrm{a}_{\mathrm{i}}\right\}$ for the designs in Example 1.

These expressions only require inverting the $n \times n V_{s s}$ (where $n$ is usually at most $m / 5$ ), and the $\mathrm{c} \times \mathrm{c} \mathrm{M}_{1}$, and give bounds for the criteria values. Note that $\mathrm{a}_{1}$ and $\mathrm{a}_{2}$ only depend on the positions of the control plots. They do not depend on c, and if $c>1$ they do not depend on the arrangement of the controls within the control plots. Also, given the set of control plots, if $\mathrm{c}>1$ different allocations of the control varieties only require changing $\mathrm{M}_{1}$ and $\mathrm{M}_{2}$. Over these different allocations, usually $\mathrm{a}_{3}-\mathrm{a}_{4}$, and hence the $\mathrm{A}_{\mathrm{nn}}$-value, only differs relatively slightly, and can be the same as when $\mathrm{c}=1$. Updating formulae can be used for $\mathrm{V}_{\mathrm{ss}}{ }^{-1}$ under variety exchanges.

The term $a_{5}$ in the $A_{n s}$-value (but not the $A_{n n}$-value) suggests differences in the $A_{n s}$-value between a good and a bad design for the control varieties. A good one would have like replicates well separated.

Unless the dependence is very weak or $t$ is small, the dominant term in the $A_{n n}$-value is $a_{1}$. As the dependence becomes stronger, this term also dominates the $A_{n s}$-value, so that the two criteria values are then highly correlated, and the efficient designs under the two criteria (and the A-criterion) become very similar. To make $\mathrm{a}_{1}$ small, it is necessary that the number of adjacencies (taking account of the relative strengths of the correlations in the two directions) between check plots and new variety plots is maximized. This leads to well separated check plots (at least in the dominant direction).

Even though these formulae are useful in seeing what design features affect efficiency under the two criteria, it is not easy to see all the effects. However, it is possible to use these formulae to obtain approximations for low and high correlations, and the elements of these approximations can be interpreted.

Example 2. Suppose $\mathrm{p}_{1}=5, \mathrm{p}_{2}=1, \mathrm{~m}=5, \mathrm{c}=1, \mathrm{r}_{1}=2, \mathrm{n}=2$, $\mathrm{t}=3$, with an AR1 process, $\rho_{1}=\alpha$.

There are 6 possible designs $D(i, j)=\{i, j\}$ for the two control plots (since $\{1,2\}$ is equivalent to $\{4,5\}$, etc.). Thus all designs can be compared, and the known expression for $\mathrm{V}^{-1}$, plus the small $\mathrm{m}$, mean that exact expressions in $\alpha$ for the criteria values can be found (Martin et al., 2000). 
Even in this very simple case, it is not obvious from the exact formulae which designs are good under the two criteria. Approximations to the values can be obtained by power-series expansions for low $|\alpha|$, or high $\alpha=1-\varepsilon$. Table 2 gives the approximations to $3 \times\left(A_{n n}\right.$-value $)$ for low correlations, $(3 / \varepsilon) \times\left(\mathrm{A}_{n n}\right.$-value $)$ for high $\alpha, 6 \times\left(\mathrm{A}_{n s}\right.$-value $)$ for low correlations, and $(3 / \varepsilon) \times\left(A_{n s}-\right.$ value $)$ for high $\alpha$. The expansions for low correlations are given in the general form from $\S 3$, and for the AR1 with low $|\alpha|$ have $\rho_{2}=\rho_{1}^{2}=\alpha^{2}$.

These approximations show that for the $A_{n n}$-criterion, $D(1,5)$ is best for low $\alpha>0$ (and $D(1,2)$ is close), and $\mathrm{D}(1,5)$ for high $\alpha$; and that for the $A_{n s}$-criterion, $D(2,4)$ is best for low $\alpha>0$, and $\mathrm{D}(1,4)$ for high $\alpha$ (and $\mathrm{D}(2,4)$ and $\mathrm{D}(1,5)$ are close).

Precise comparisons show that $\mathrm{D}(1,5)$ is $\mathrm{A}_{\mathrm{nn}}$-optimal for all $\alpha>0$. The $\mathrm{A}_{\mathrm{ns}}$-optimal designs are $\mathrm{D}(2,4)$ for $0<\alpha<0.518$, and $\mathrm{D}(1,4)$ for $\alpha>0.518$, although $\mathrm{D}(1,4)$ is highly $\mathrm{A}_{\mathrm{ns}}$-efficient for all $\alpha>0$ (minimum efficiency of 0.979 at $\alpha \approx 0.22$ ). At $\alpha=0.5$, the efficiency of the worst design is $0.707\left(A_{n n}\right)$ and $0.632\left(A_{n s}\right)$. Note that for low $\alpha>0, D(1,2)$ is $A_{n s}$-worst, but very $A_{n n}$-efficient.

Evaluations suggest that the linear approximation in $\alpha$ is reasonable (errors up to about $5 \%$ ) for $\alpha$ up to about 0.2 , the quadratic approximation in $\alpha$ up to about 0.4 , and the high $\alpha$ approximation from about 0.7. []

\section{Approximations to the criteria values}

For $\left|\rho_{1}\right|,\left|\rho_{2}\right|$ and $\rho_{1}^{2}$, small, and all other $\rho_{g}$ negligible, the general formula for the low-order approximation with $\mathrm{p}_{2}=1$ is (Martin et al., 2000):

$$
\begin{gathered}
\{\mathrm{t}(\mathrm{t}-1) / 2\} \times\left(\mathrm{A}_{\mathrm{nn}}-\mathrm{value}\right) \approx \mathrm{t}(\mathrm{t}-1)-2\left(\mathrm{~m}_{1} \rho_{1}+\mathrm{m}_{2} \rho_{2}\right)-\mathrm{tk}_{3} \rho_{1}^{2} \text {, and } \\
\mathrm{ct} \times\left(\mathrm{A}_{\mathrm{ns}}-\text { value }\right) \approx \mathrm{ct}+\mathrm{t} \Sigma \mathrm{r}_{\mathrm{i}}^{-1}-2\left(\mathrm{k}_{1}-\mathrm{tl}_{1}\right) \rho_{1}-2\left(\mathrm{k}_{2}-\mathrm{tl}_{2}\right) \rho_{2}-\left\{\mathrm{ck}_{4}-2\left(\mathrm{k}_{5}-\mathrm{tl}_{3}\right)\right\} \rho_{1}{ }^{2} .
\end{gathered}
$$

In these formulae, the $\mathrm{m}_{\mathrm{i}}$ depend on new-new adjacencies (or lag 2 adjacencies); the $\mathrm{k}_{\mathrm{i}}$ on control-new adjacencies (or lag 2 adjacencies); and the $\mathrm{l}_{\mathrm{i}}$ on like-like control adjacencies (or lag 2 adjacencies).

The coefficients in the approximation formula can be interpreted to show that the $A_{n n}$-efficient designs for low correlations have as many new-new adjacencies as possible. This occurs when the controls plots are all at the two ends (or one end), in any order. The $A_{n n}$-worst designs have the controls separated and not at the ends.

The $\mathrm{A}_{\mathrm{ns}}$-efficient designs for low correlations have as few like-like control adjacencies, and as many new-control adjacencies, as possible. This occurs when the controls plots are all separated. When there are control-control adjacencies and $c>1$, the $A_{n s}$-value varies more with 
how many are like-like adjacencies than the $A_{n n}$-value. The $A_{n s}$-worst designs have the like controls all together, and all the controls at one end.

The $A_{n s}$-efficient designs for low correlations are $A_{n n}$-inefficient. Similarly, some of the $A_{n n}{ }^{-}$ efficient designs are $A_{n s}$-inefficient. If $c>1$, some of the $A_{n n}$-efficient designs are not so $A_{n s^{-}}$ inefficient.

The low-correlation approximation for $\mathrm{p}_{1}, \mathrm{p}_{2}>1$ is considerably more involved (Martin et al., 2000), and is not given here, although essentially the same interpretation holds. The $A_{n n}{ }^{-}$ efficient designs for low correlations have many new-new adjacencies, and the $\mathrm{A}_{\mathrm{ns}}$-efficient designs have many new-control adjacencies, with few like-like control adjacencies.The approximations for high correlations are more complicated (Martin et al., 2000), and also are not given here, but for both criteria suggest spacing out the control plots for efficient designs.

\section{A two-dimensional example}

Consider in detail the case of in Example 1: $\mathrm{p}_{1}=5, \mathrm{p}_{2}=10, \mathrm{~m}=50, \mathrm{c}=2, \mathrm{r}_{1}=\mathrm{r}_{2}=5, \mathrm{n}=10, \mathrm{t}=40$. Use of the algorithm shows that some common types of designs arise as efficient or inefficient.

The aligned design $\mathrm{DA}\left(\left\{\mathrm{i}_{1}, \mathrm{i}_{2}, \ldots\right\} \times\left\{\mathrm{j}_{1}, \mathrm{j}_{2}, \ldots\right\}\right)$ has the control plots are the intersections of rows $\mathrm{i}_{1}, \mathrm{i}_{2}, \ldots$ and columns $\mathrm{j}_{1}, \mathrm{j}_{2}, \ldots$. This includes the row design $\mathrm{DR}\left(\mathrm{i}_{1}, \mathrm{i}_{2}, \ldots\right)$, when the controls completely fill rows $\mathrm{i}_{1}, \mathrm{i}_{2}, \ldots$, and the corresponding column design $\mathrm{DC}\left(\mathrm{j}_{1}, \mathrm{j}_{2}, \ldots\right)$. These are all systematic designs. An additional set of systematic designs uses diagonals. A subscript ' $r$ ' after DA, DR, DC or DD indicates all the like controls are together (i.e. repeated $1111 \ldots$ ), and 'a' for alternate (e.g. 1212...).

The other types of designs have control units well separated:

A scattered design DS has no row or column control-control adjacencies.

A scattered interior design DSI is a DS design which also has no controls along the edges.

A knight's move design DKM is a DS design which also has no diagonal control-control adjacencies, and no row or column lag 2 control-control adjacencies, so that the control plots are all at least a knight's move apart.

Some examples of the best and worst designs found by an algorithmic search and theory for an AR1*AR1 with some different $\left(\rho_{1,0}, \rho_{0,1}\right)$ are given in Table 3 . DA(1) denotes $\mathrm{DA}(\{2,4\} \times\{2,4$, $6,8,10\})$, and $\mathrm{DO}$ denotes other designs (DO(1) has a row adjacency between control 1 and control 2). The best designs are shown in Figure 5.

Evaluations for the AR1*AR1 suggest that the first-order approximations are reasonable (up to $5 \%$ relative error) for $\rho_{1,0}, \rho_{0,1}$ up to about 0.25 , and that the second-order approximations are reasonable (up to $5 \%$ relative error) for $\rho_{1,0}, \rho_{0,1}$ up to about 0.45 . Using the algorithm for finding efficient designs suggests that for higher correlations, the determinants of efficiency are similar to those for moderate correlations. 
Table 4 shows the second-order approximations for the designs in Example 1. Although $\rho_{0,1}=$ 0.6 is too high for the approximations to work well, they do indicate clearly how the different designs and cases of them affect the two criteria values. Over the three cases for each design, the $\mathrm{A}_{\mathrm{nn}}$-approximations hardly differ, but the $\mathrm{A}_{\mathrm{ns}}$-approximations do. Both approximations differ markedly between the two designs.

The approximations and the best/worst designs confirm that for both criteria the worst designs have the like controls close together (but for the $A_{n n}$-criterion, the alternating designs have very similar values). If $v=\rho_{1,0} / \rho_{0,1}$ is small or large, an alternating column or row design, respectively, is best (with a wider range of $v$ for the $A_{n n}$-criterion). For $v$ close to 1 , the best designs have the controls well-separated (unless the correlations are very small with the $A_{n n}{ }^{-}$ criterion).

The best designs for one $\left(\rho_{1,0}, \rho_{0,1}\right)$ can have very poor robustness to quite different correlations. For $\left(\rho_{1,0}, \rho_{0,1}\right)=(0.1,0.9)$ the relative efficiencies of the optimal designs under $(0.9,0.1)$ are $0.180\left(A_{n s}\right)$ and $0.301\left(A_{n n}\right)$. For $\left(\rho_{1,0}, \rho_{0,1}\right)=(0.9,0.1)$ the relative efficiencies of the optimal designs under $(0.1,0.9)$ are $0.302\left(A_{n s}\right)$ and $0.360\left(A_{n n}\right)$. Note that, apart from the change from alternating to repeated (which does not greatly affect the $A_{n n}$-value), the $A_{n n}$-best at $(0.1,0.9)$ is the $A_{n n}$-worst at $(0.9,0.1)$ and vice-versa. In practice, it would be very unusual to predict the correlations this badly. The designs in Figure 5 suggest that if the dependence is stronger in one direction, the check plots only need to be spread fairly evenly along that direction. However, for some $\left(\rho_{1,0}, \rho_{0,1}\right)$ there are some obvious differences in the designs obtained under the two criteria. Table 5 shows that the robustness is usually not too bad provided the actual correlations are not too different from those used to obtain the design. Diagonal designs are reasonably efficient, but don't arise as the best designs (or the worst).

These comments explain fairly well the different designs shown in Figure 5. With unreplicated trials, it is usually sensible to seek high efficiency rather than optimality, which in any case cannot usually be obtained. Efficiency of a design under the $A_{n n}$-criterion can be unstable as the strength of the dependence increases.

Most of the designs in Figure 5 have the check plots at least fairly systematically arranged, and would not give good information on spatial dependence at some of the low lags which would be important for estimating the spatial process. The effect of using an additional criterion for the efficient estimation of the spatial dependence has not yet been investigated fully, but it is clear intuitively that some check plots should be close together. For the $\mathrm{A}_{n \mathrm{n}}$-criterion on the mean effects, these close check plots should (if $\mathrm{c}>1$ ) have different varieties. 


\section{Summary}

For small $t$ and small correlations, the $\mathrm{A}_{\mathrm{nn}}$ - and $\mathrm{A}_{\mathrm{ns}}$-efficient designs can look very different, although the relative efficiency of one to the other may still be quite high. For larger $t$ and/or larger correlations, both criteria values mainly depend on $\operatorname{tr}\left(\mathrm{V}_{\mathrm{nn} . \mathrm{s}}\right)$, and tend to give very similar efficient designs. These tend to have, along the direction of stronger correlations, a minimal number of like controls close together, and a maximal number of test-control adjacencies, so that the controls are scattered. Although the $\mathrm{A}_{\mathrm{nn}}$-value may correlate slightly better with selection probabilities, efficient designs under the $A_{n s}$-criterion for a given $V$ will usually be more robust to other $\mathrm{V}$, and more intuitively acceptable.

Designs which allow the dependence to be estimated also have been considered in some of the situations, and usually the designs have some sites close together. In these cases, there may not be a confident prior form for the dependence structure, so that being able to estimate a general process is important. With unreplicated trials, there often is confidence in the form of the dependence structure, so that good designs for that structure, but robust to small differences in the structure, are required.

Chauhan et al. (2000) investigated the efficiency of some systematic unreplicated designs. A general recommendation from that and the results here would be that the control plots, and the replicates of each control, should be as well separated as possible, particularly in the direction of stronger dependence. If possible, designs in which the control plots are at least a knight's move apart are usually very efficient unless the dependence is much stronger in one direction. If the dependence is much stronger across the rows, say, designs with control plots filling separated columns, preferably with the replicates of each control well separated, can be very efficient.

Acknowledgements

We are grateful to Brian Cullis of the Wagga Wagga Agricultural Institute for motivating this research, and for his assistance on the practicalities of the design and analysis of unreplicated trials; and to the late Rob Kempton for further discussions on the topic. RJM is grateful for support provided by the Department of Statistics, North Carolina State University.

\section{References}

Besag, J. and Kempton, R. (1986). Statistical analysis of field experiments using neighbouring plots. Biometrics 42, 231-251.

Chan, B., Eccleston, J. A., Martin, R. J. and Chauhan, N. (1999). On the construction of unreplicated designs with spatially correlated data. Preprint.

Chauhan, N., Chan, B., Eccleston, J. A. and Martin, R. J. (2000). On the efficiency of systematic designs in unreplicated trials. Preprint.

Cullis, B., Gogel, B., Verbyla, A. and Thompson, R. (1998). Spatial analysis of multienvironment early generation variety trials. Biometrics 54, 1-18. 
Cullis, B. R., Lill, W. J., Fisher, J. A., Read, B. J. and Gleeson, A. C. (1989). A new procedure for the analysis of early generation variety trials. Applied Statistics, 38, 361-375.

Federer, W. T. and Raghavarao, D. (1975). On augmented designs. Biometrics 31, 29-35.

Gilmour, A. R., Thompson, R. and Cullis, B. R. (1995). Average information REML: an efficient algorithm for variance parameter estimation in linear mixed models. Biometrics 51, 1440-1450.

Kempton, R. A. (1984). The design and analysis of unreplicated field trials. Vorträge für Pflanzenzüchtung 7, 219-242.

Kempton, R. A. and Talbot, M. (1988). The development of new crop varieties. J. Roy. Statist. Soc. A 151, 327-341.

Maas, T., Marx, D. and Pedersen. J. (2002). Unreplicated spatial designs compared using optimality criteria. In 'Proceedings of the 2002 Kansas State University Conference on Applied Statistics in Agriculture', 84-93. Kansas State University, Manhattan, KS.

Maas, T., Stafford, J., Sebolai, B., Marx, D., Travnicek and Pedersen. J. (2003). Unreplicated variey trials: effects of check plot density and fixed versus random treatments. In 'Proceedings of the 2003 Kansas State University Conference on Applied Statistics in Agriculture', 180-190. Kansas State University, Manhattan, KS.

Martin, R. J. (2001). Comparing and contrasting some environmental and experimental design problems. Environmetrics 12, 273-287.

Martin, R. J., Chauhan, N., Eccleston, J. A. and Chan, B. (2000). Some theoretical results on unreplicated designs for dependent observations. Research Report 494/00. Department of Probability and Statistics, University of Sheffield.

Martin, R. J. and Eccleston, J. A. (1997). Construction of optimal and near-optimal designs for dependent observations using simulated annealing. Research Report 479/97. Department of Probability and Statistics, University of Sheffield. 
Figure 1. An unreplicated design with $\mathrm{p}_{1}=\mathrm{p}_{2}=4, \mathrm{t}=12, \mathrm{c}=2, \mathrm{r}_{1}=\mathrm{r}_{2}=2, \mathrm{n}=4$ :

\begin{tabular}{|cccc|}
\hline 1 & 3 & 4 & 1 \\
5 & 6 & 7 & 8 \\
9 & 10 & 11 & 12 \\
2 & 13 & 14 & 2 \\
\hline
\end{tabular}

all labels

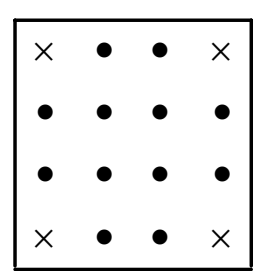

\begin{tabular}{|llll|}
\hline 1 & $\bullet$ & $\bullet$ & 1 \\
$\bullet$ & $\bullet$ & $\bullet$ & $\bullet$ \\
$\bullet$ & $\bullet$ & $\bullet$ & $\bullet$ \\
2 & $\bullet$ & $\bullet$ & 2 \\
\hline
\end{tabular}

check plot positions check variety labels only

Figure 2. Some different plot shapes for $3 \times 3$ layouts
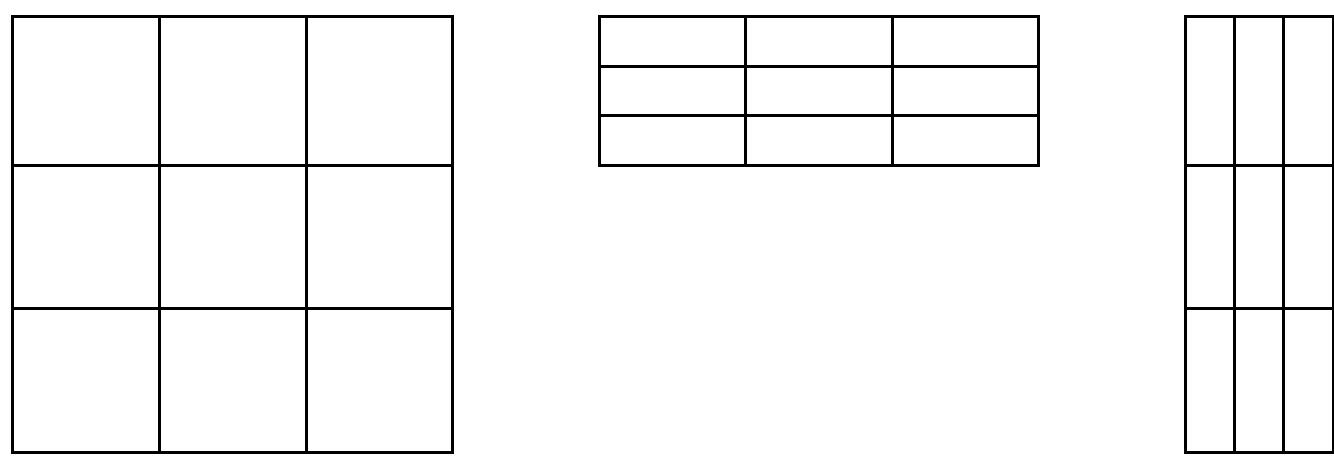

Figure 3. Examples of systematic layouts of controls

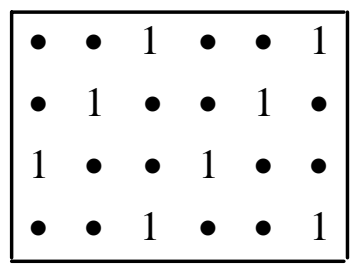

\begin{tabular}{|llllllllllllllllllllllllllllllll}
\hline 1 & $\bullet$ & $\bullet$ & $\bullet$ & $\bullet$ & $\bullet$ & 2 & $\bullet$ & $\bullet$ & $\bullet$ & $\bullet$ & $\bullet$ & 3 & $\bullet$ & $\bullet$ & $\bullet$ & $\bullet$ & $\bullet$ & 4 & $\bullet$ & $\bullet$ & $\bullet$ & $\bullet$ & $\bullet$ & 1 & $\bullet$ & $\bullet$ & $\bullet$ \\
$\bullet$ & $\bullet$ & $\bullet$ & 3 & $\bullet$ & $\bullet$ & $\bullet$ & $\bullet$ & $\bullet$ & 4 & $\bullet$ & $\bullet$ & $\bullet$ & $\bullet$ & $\bullet$ & 1 & $\bullet$ & $\bullet$ & $\bullet$ & $\bullet$ & $\bullet$ & 2 & $\bullet$ & $\bullet$ & $\bullet$ & $\bullet$ & $\bullet$ & 3 \\
4 & $\bullet$ & $\bullet$ & $\bullet$ & $\bullet$ & $\bullet$ & 1 & $\bullet$ & $\bullet$ & $\bullet$ & $\bullet$ & $\bullet$ & 2 & $\bullet$ & $\bullet$ & $\bullet$ & $\bullet$ & $\bullet$ & 3 & $\bullet$ & $\bullet$ & $\bullet$ & $\bullet$ & $\bullet$ & 4 & $\bullet$ & $\bullet$ & $\bullet$ \\
$\bullet$ & $\bullet$ & $\bullet$ & 2 & $\bullet$ & $\bullet$ & $\bullet$ & $\bullet$ & $\bullet$ & 3 & $\bullet$ & $\bullet$ & $\bullet$ & $\bullet$ & $\bullet$ & 4 & $\bullet$ & $\bullet$ & $\bullet$ & $\bullet$ & $\bullet$ & 1 & $\bullet$ & $\bullet$ & $\bullet$ & $\bullet$ & $\bullet$ & 2 \\
3 & $\bullet$ & $\bullet$ & $\bullet$ & $\bullet$ & $\bullet$ & 4 & $\bullet$ & $\bullet$ & $\bullet$ & $\bullet$ & $\bullet$ & 1 & $\bullet$ & $\bullet$ & $\bullet$ & $\bullet$ & $\bullet$ & 2 & $\bullet$ & $\bullet$ & $\bullet$ & $\bullet$ & $\bullet$ & 3 & $\bullet$ & $\bullet$ & $\bullet$ \\
\hline
\end{tabular}


Figure 4. Estimated selection probabilities plotted against $A_{n s}$ - and $A_{n n}$-values

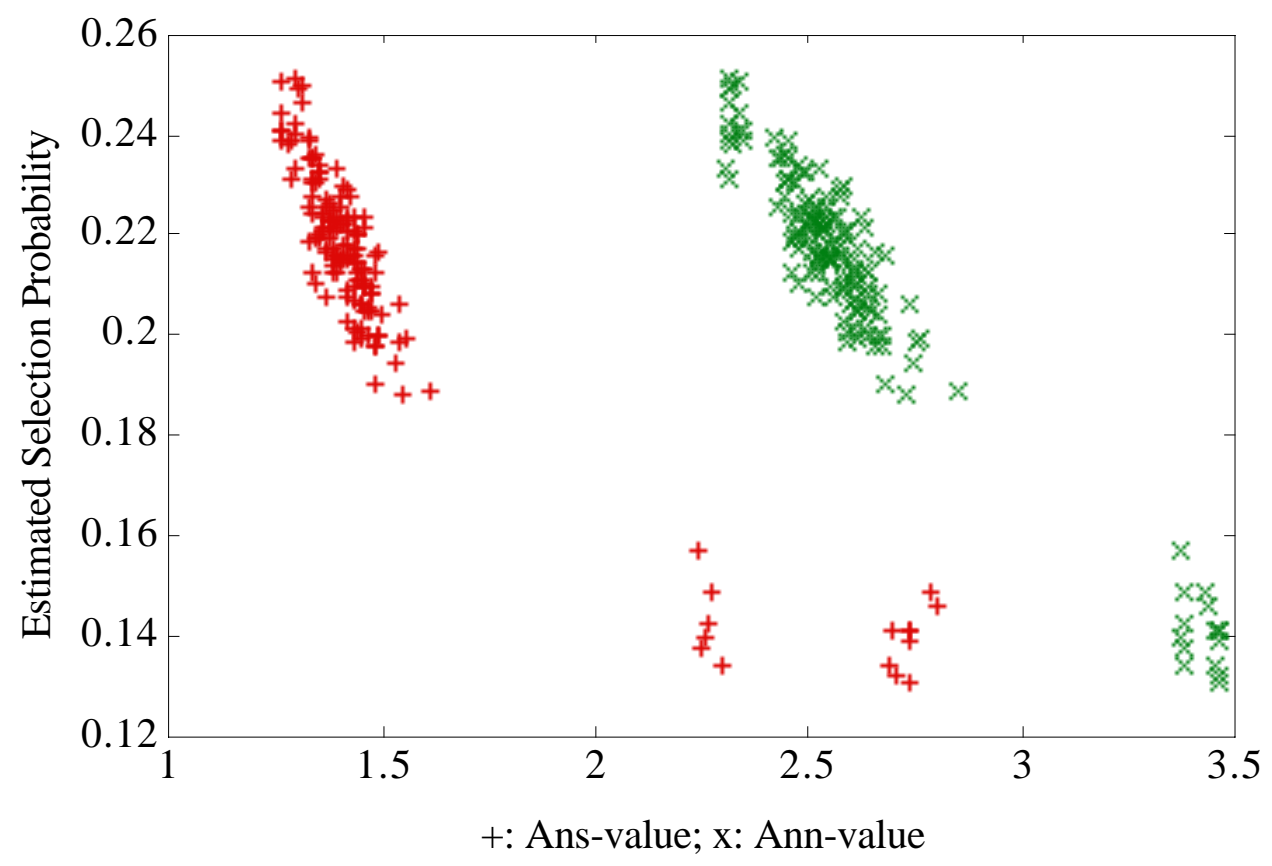

Figure 5. $A_{n s}$ and $A_{n n}$-efficient designs for a $5 \times 10$ layout with $\mathrm{c}=2, \mathrm{r}=5$, under an AR1*AR1 and different $\left(\rho_{1,0}, \rho_{0,1}\right)$ :
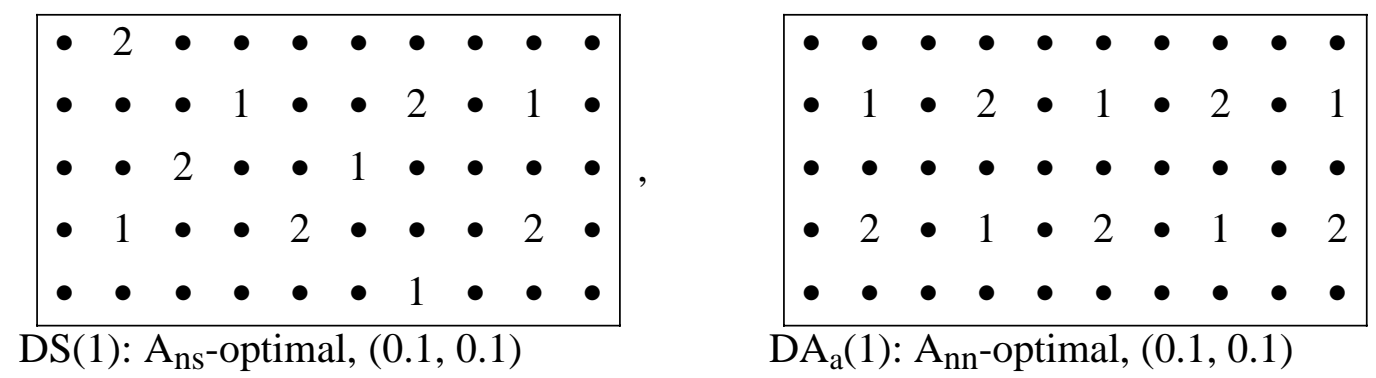


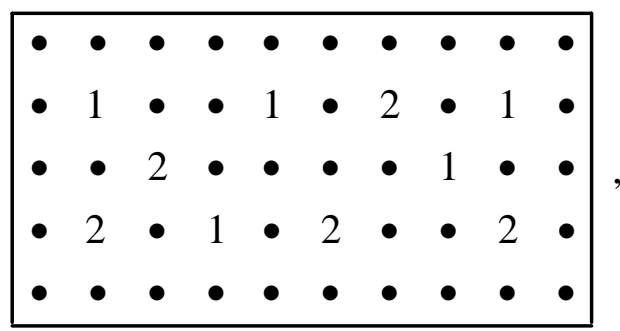

DSI(1): $A_{\mathrm{ns}^{-}}$optimal, $(0.5,0.5)$

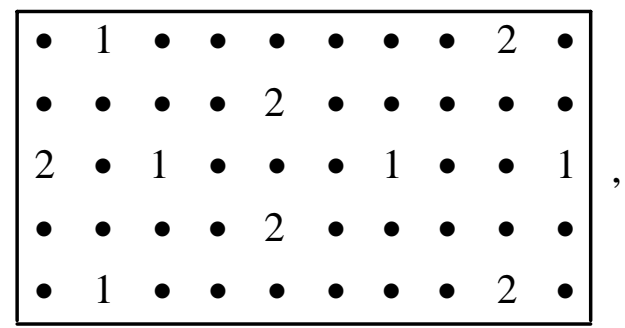

DS(3): Ans $_{\text {-optimal, }}(0.9,0.9)$

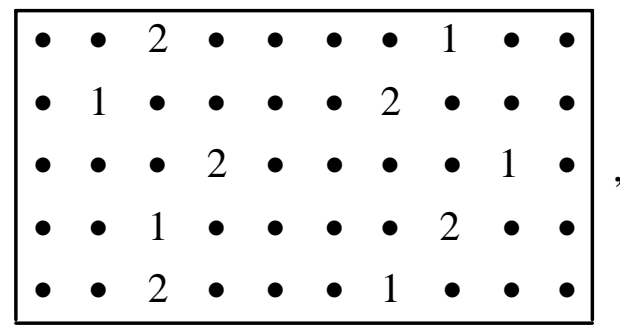

DO(1): $A_{n s}$-optimal, $(0.2,0.6)$

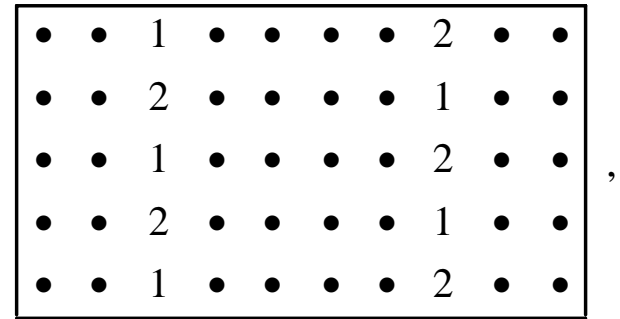

$\mathrm{DC}_{\mathrm{a}}(3,8): \mathrm{A}_{n n^{-}}$and $\mathrm{A}_{n \mathrm{n}^{-}}$optimal, $(0.1,0.9)$

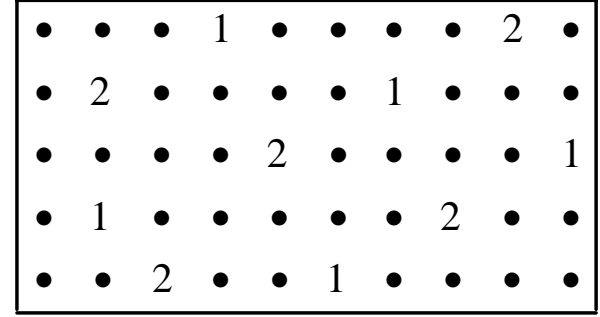

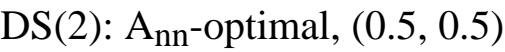

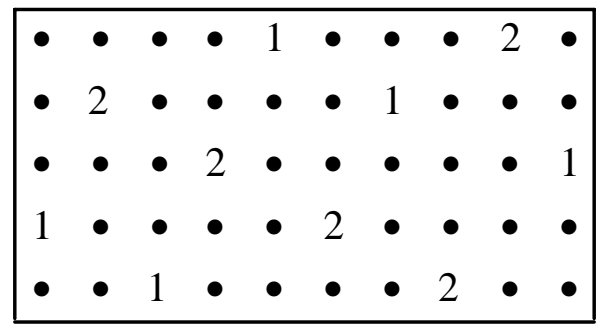

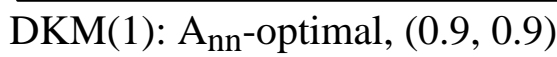
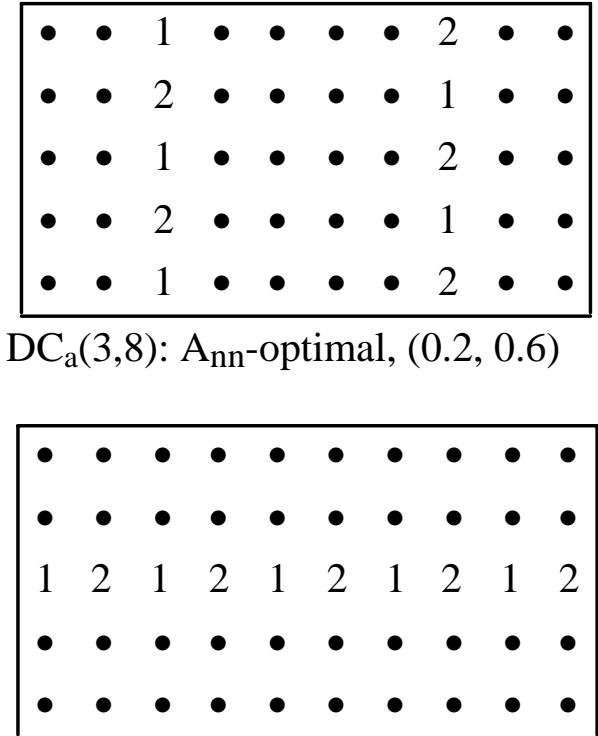

$\mathrm{DR}_{\mathrm{a}}(3): \mathrm{A}_{\mathrm{nn}}$ and $\mathrm{A}_{\mathrm{ns}} \mathrm{opptimal}(0.9,0.1)$ 
Table 1. A-, $A_{n n}-, A_{n s}-$, and $A_{s s}$-values and the $a_{i}$ for some designs with $p_{1}=5, p_{2}=10, m=50$, $\mathrm{c}=2, \mathrm{r}_{1}=\mathrm{r}_{2}=5, \mathrm{n}=10, \mathrm{t}=40$

\begin{tabular}{ccccccccccc}
\multicolumn{10}{c}{$\mathrm{V}=\mathrm{I}_{\mathrm{m}}$} \\
$\mathrm{c}$ & $\mathrm{A}-$ & $\mathrm{A}_{\mathrm{nn}^{-}}$ & $\mathrm{A}_{\mathrm{ns}^{-}}$ & $\mathrm{A}_{\mathrm{ss}^{-}}$ & $\mathrm{a}_{1}$ & $\mathrm{a}_{2}$ & $\mathrm{a}_{3}$ & $\mathrm{a}_{4}$ & $\mathrm{a}_{5}$ & $\mathrm{a}_{6}$ \\
\cline { 2 - 12 } $\mathrm{c}=1$ & 1.924 & 2 & 1.2 & 0.4 & 40 & 1 & 0 & 0 & 0.4 & 0 \\
1.956 & 2 & 1.1 & 0 & 40 & 1 & 0 & 0 & 0.1 & 0
\end{tabular}

\begin{tabular}{r|cccc|cccccc}
\multicolumn{1}{c}{} & $\mathrm{A}-$ & $\mathrm{A}_{\mathrm{nn}^{-}}$ & $\mathrm{A}_{\mathrm{ns}^{-}}$ & $\mathrm{A}_{\mathrm{ss}}{ }^{-}$ & $\mathrm{a}_{1}$ & $\mathrm{a}_{2}$ & $\mathrm{a}_{3}$ & $\mathrm{a}_{4}$ & $\mathrm{a}_{5}$ & $\mathrm{a}_{6}$ \\
\cline { 2 - 12 } $\mathrm{DC}_{\mathrm{a}}(3,8)$ & 1.404 & 1.462 & 0.856 & 0.264 & 29.783 & 1.868 & 2.323 & 1.732 & 0.426 & 6.383 \\
$\mathrm{DC}_{\mathrm{r}}(3,8)$ & 1.433 & 1.486 & 0.927 & 0.503 & 29.783 & 1.868 & 2.786 & 1.732 & 0.546 & 6.383 \\
$\mathrm{DC}_{1}(3,8)$ & 1.404 & 1.436 & 0.777 & 0 & 29.783 & 1.868 & 1.813 & 1.732 & 0.147 & 3.191 \\
\hline $\mathrm{DR}_{\mathrm{a}}(3)$ & 1.763 & 1.818 & 1.247 & 0.108 & 39.168 & 3.812 & 0.279 & 0.177 & 0.669 & 2.954 \\
$\mathrm{DR}_{\mathrm{r}}(3)$ & 1.779 & 1.823 & 1.365 & 0.571 & 39.168 & 3.812 & 0.375 & 0.177 & 0.901 & 2.954 \\
$\mathrm{DR}_{1}(3)$ & 1.788 & 1.817 & 1.219 & 0 & 39.168 & 3.812 & 0.256 & 0.177 & 0.308 & 1.477
\end{tabular}

Table 2. Approximations to $3 \times\left(A_{n n}\right.$-value) for low correlations, $(3 / \varepsilon) \times\left(A_{n n}\right.$-value $)$ for high $\alpha$, $6 \times\left(A_{n s}-\right.$ value $)$ for low correlations, and $(3 / \varepsilon) \times\left(A_{n s}-\right.$ value $)$ for high $\alpha$

\begin{tabular}{|c|c|c|c|c|}
\hline & $3 \times A_{n n}$ & $(3 / \varepsilon) \times \mathrm{A}_{\mathrm{nn}}$ & $6 \times A_{n s}$ & $(3 / \varepsilon) \times A_{n s}$ \\
\hline $\mathrm{D}(1,2)$ & $6-4 \rho_{1}-2 \rho_{2}-\rho_{1}^{2}$ & $8-2 \varepsilon$ & $9+\rho_{1}-4 \rho_{2}-\rho_{1}^{2}$ & $12-8 \varepsilon$ \\
\hline $\mathrm{D}(1,3)$ & $6-2 \rho_{1}-2 \rho_{2}-\rho_{1}^{2}$ & $10-\varepsilon$ & $9-6 \rho_{1}+\rho_{2}-\rho_{1}^{2}$ & $7-3 \varepsilon / 2$ \\
\hline $\mathrm{D}(1,4)$ & $6-2 \rho_{1}-2 \rho_{2}-4 \rho_{1}^{2}$ & $8+2 \varepsilon$ & $9-6 \rho_{1}-4 \rho_{2}-3 \rho_{1}^{2}$ & $14 / 3+4 \varepsilon / 3$ \\
\hline $\mathrm{D}(1,5)$ & $6-4 \rho_{1}-2 \rho_{2}-3 \rho_{1}^{2}$ & $5+5 \varepsilon / 2$ & $9-4 \rho_{1}-4 \rho_{2}-2 \rho_{1}^{2}$ & $5+5 \varepsilon / 2$ \\
\hline $\mathrm{D}(2,3)$ & $6-2 \rho_{1} \quad-3 \rho_{1}^{2}$ & $12-8 \varepsilon$ & $9-\rho_{1}-6 \rho_{2}-2 \rho_{1}^{2}$ & $8-2 \varepsilon$ \\
\hline $\mathrm{D}(2,4)$ & $6-4 \rho_{2}-3 \rho_{1}^{2}$ & $10-\varepsilon$ & $9-8 \rho_{1}+3 \rho_{2}-2 \rho_{1}^{2}$ & $5+\varepsilon / 2$ \\
\hline
\end{tabular}

Table 3. The best and worst designs for an AR1*AR1 with some different $\left(\rho_{1,0}, \rho_{0,1}\right)$

\begin{tabular}{|c|c|c|c|c|c|c|}
\hline & $(0.1,0.1)$ & $(0.5,0.5)$ & $\begin{array}{l}\left(\rho_{1,0}, \rho_{0,1}\right) \\
(0.9,0.9)\end{array}$ & $(0.2,0.6)$ & $(0.1,0.9)$ & $(0.9,0.1)$ \\
\hline$A_{n n-b e s t}$ & $\mathrm{DA}_{\mathrm{a}}(1)$ & DSI(1) & DS(3) & $\mathrm{DC}_{\mathrm{a}}(3,8)$ & $\mathrm{DC}_{\mathrm{a}}(3,8)$ & $\mathrm{DR}_{\mathrm{a}}(3)$ \\
\hline 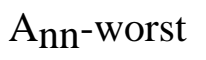 & $\mathrm{DC}_{\mathrm{r}}(1,2)$ & $\mathrm{DC}_{\mathrm{r}}(1,2)$ & $\mathrm{DC}_{\mathrm{r}}(1,2)$ & $\mathrm{DR}_{\mathrm{r}}(3)$ & $\mathrm{DR}_{\mathrm{r}}(3)$ & $\mathrm{DC}_{\mathrm{r}}(3,8)$ \\
\hline$A_{n s}$-best & $\mathrm{DS}(1)$ & $\mathrm{DS}(2)$ & $\operatorname{DKM}(1)$ & $\mathrm{DO}(1)$ & $\mathrm{DC}_{\mathrm{a}}(3,8)$ & $\mathrm{DR}_{\mathrm{a}}(3)$ \\
\hline Ans-worst & $\mathrm{DC}_{\mathrm{r}}(1,2)$ & $\mathrm{DC}_{\mathrm{r}}(1,2)$ & $\mathrm{DC}_{\mathrm{r}}(1,2)$ & $\mathrm{DR}_{\mathrm{r}}(1)$ & $\mathrm{DR}_{\mathrm{r}}(1)$ & $\mathrm{DC}_{\mathrm{r}}(1,2)$ \\
\hline
\end{tabular}


Table 4. The coefficients in the approximations to the $\left\{\left(\mathrm{A}_{\mathrm{nn}}\right.\right.$-value) -2$\} \times 39 / 2$ (rows 1 to 6$)$ and the $\left\{\left(\mathrm{A}_{\mathrm{ns}}\right.\right.$-value) $\left.-1-\mathrm{c} / 10\right\} \times 100$ (rows 7 to 12$)$ for the $\mathrm{DC}(3,8)$ and $\mathrm{DR}(3)$ designs.

\begin{tabular}{l|lllllllll}
\multicolumn{1}{c}{} & $\rho_{1,0}$ & $\rho_{0,1}$ & $\rho_{2,0}$ & $\rho_{0,2}$ & $\rho_{1,1}$ & $\rho_{1,-1}$ & $\rho_{1,0} 2$ & $\rho_{0,1} 2$ & $\rho_{1,0} \rho_{0,1}$ \\
\cline { 2 - 10 } $\mathrm{DC}_{\mathrm{a}}(3,8)$ & -1.6 & -1.25 & -1.2 & -1 & -1 & -1 & 0 & -16 & 0 \\
$\mathrm{DC}_{\mathrm{r}}(3,8)$ & -1.6 & -1.25 & -1.2 & -1 & -1 & -1 & 0 & -16 & 0 \\
$\mathrm{DC}_{1}(3,8)$ & -1.6 & -1.25 & -1.2 & -1 & -1 & -1 & 0 & -18 & 0 \\
$\mathrm{DR}_{\mathrm{a}}(3)$ & -1 & -1.8 & -0.5 & -1.6 & -0.9 & -0.9 & -16 & 0 & 0 \\
$\mathrm{DR}_{\mathrm{r}}(3)$ & -1 & -1.8 & -0.5 & -1.6 & -0.9 & -0.9 & -16 & 0 & 0 \\
$\mathrm{DR}_{1}(3)$ & -1 & -1.8 & -0.5 & -1.6 & -0.9 & -0.9 & -18 & 0 & 0 \\
$\mathrm{DC}_{\mathrm{a}}(3,8)$ & 0 & -10 & 24 & -10 & -8 & -8 & -4.8 & -40 & 0 \\
$\mathrm{DC}_{\mathrm{r}}(3,8)$ & 32 & -10 & 24 & -10 & -8 & -8 & -4.8 & -40 & 0 \\
$\mathrm{DC}_{1}(3,8)$ & 16 & -10 & 12 & -10 & -8 & -8 & -2.4 & -45 & 0 \\
$\mathrm{DR}_{\mathrm{a}}(3)$ & -10 & 0 & -10 & 32 & -9 & -9 & -40 & -3.2 & 0 \\
$\mathrm{DR}_{\mathrm{r}}(3)$ & -10 & 32 & -10 & 24 & -9 & -9 & -40 & -8 & 0 \\
$\mathrm{DR}_{1}(3)$ & -10 & 18 & -10 & 16 & -9 & -9 & -45 & -1.6 & 0
\end{tabular}

Table 5. $A_{n n^{-}}$(upper value) and $A_{n s^{-}}$(lower value) efficiencies for some $\left(\rho_{1,0}, \rho_{0,1}\right)$

\begin{tabular}{l|l|l|l|l|l}
\multicolumn{1}{l}{$\begin{array}{l}\text { Tssumed } \\
\text { value }\end{array}$} & $(0.5,0.5)$ & $(0.4,0.6)$ & $(0.3,0.7)$ & $(0.2,0.8)$ & $(0.1,0.9)$ \\
\hline$(0.5,0.5)$ & 1 & 0.986 & 0.925 & 0.768 & 0.491 \\
& 1 & 0.999 & 0.985 & 0.941 & 0.903 \\
\hline$(0.4,0.6)$ & 0.982 & 1 & 0.996 & 0.962 & 0.939 \\
& 0.995 & 1 & 0.992 & 0.951 & 0.914 \\
\hline$(0.3,0.7)$ & 0.953 & 0.986 & 1 & 0.985 & 0.987 \\
& 0.980 & 0.993 & 1 & 0.979 & 0.958 \\
\hline$(0.2,0.8)$ and & 0.904 & 0.961 & 0.999 & 1.000 & 1.000 \\
$(0.1,0.9)$ & 0.857 & 0.931 & 0.988 & 1.000 & 1.000
\end{tabular}

